\title{
HUBUNGAN PENGETAHUAN DAN DUKUNGAN KELUARGA DENGAN RUTINITAS DALAM MENGONTROL GULA DARAH PADA PENDERITA DIABETES MELITUS TIPE 2
}

\author{
Indirawaty \\ Program DIII Jurusan Keperawatan/ Poltekkes Kemenkes Makassar \\ indirawaty13@gmail.com \\ Anang Adrian \\ Program DIII Jurusan Keperawatan/ Poltekkes Kemenkes Makassar \\ Sudirman \\ Program DIII Jurusan Keperawatan/ Poltekkes Kemenkes Makassar \\ Kurnia Rahma Syarif \\ Program DIII Jurusan Keperawatan/ Poltekkes Kemenkes Makassar \\ kurniarahmasyarif@poltekkes-mks.ac.id
}

\begin{abstract}
Received: 02 Oktober 2020; Revised: 21 November 2020; Accepted: 28 Desember 2020 DOI: http://dx.doi.org/10.37905/aksara.7.1.67-78.2021
\end{abstract}

\begin{abstract}
Diabetes Mellitus is a serious chronic disease and occurs both when the pancreas does not produce enough insulin (a hormone that regulates blood glucose) or if the body cannot use the insulin produced effectively. DM sufferers are at risk of complications. These complications can be prevented by controlling diabetic blood glucose levels. Control of blood sugar levels in patients with DM is not adequate to avoid complications, the needs for knowledge and support of family with regular control of blood sugar DM patients. Method: This research was analytic descriptive with cross sectional design. The sampling technique used was random sampling with 50 respondents. Data collection was carried out using a questionnaire. Data analysis used Chi Square test with significance level $\alpha=$ 0.05. Result: Based on the results of statistical tests using test, it was found that there was correlation between family support and knowledge and controlling blood sugar levels with p-value 0,002 and there was correlation between family support in controlling blood sugar levels with $\rho$-value 0,001 and obtained $p$ value $<0,05$. Conclusion: There is a significant correlation between family support and knowledge with regular control of blood sugar in patients with type 2 diabetes mellitus in the Mangasa Health Center Makassar.
\end{abstract}

Keywords: Knowledge, Family Support, Blood Sugar, Diabetes Mellitus 


\begin{abstract}
ABSTRAK
Diabetes Mellitus merupakan penyakit kronik yang serius dan terjadi baik saat pankreas tidak menghasilkan cukup insulin (hormon yang mengatur glukosa darah) maupun jika tubuh tidak dapat menggunakan insulin yang dihasilkan secara efektif. Penderita DM berisiko mengalami komplikasi. Komplikasi tersebut dapat dicegah dengan mengendalikan kadar glukosa darah diabetesi. Pengendalian kadar gula darah pada penderita DM tersebut belum cukup untuk menghindari terjadinya komplikasi akan tetapi diperlukan adanya pengetahuan dan dukungan keluarga dengan rutinitas dalam mengontrol gula darah penderita DM.

Metode: Penelitian ini bersifat deskriptif analitik dengan desain cross sectional. Teknik sampling yang digunakan ialah random sampling dengan jumlah responden sebanyak 50 orang. Pengumpulan data dilakukan dengan menggunakan kuesioner. Analisa data menggunakan uji Chi Square dengan tingkat kemaknaan $\alpha=0,05$. Hasil: Berdasarkan hasil uji statistik menggunakan risk didapatkan ada hubungan pengetahuan dalam mengontrol kadar gula darah nilai $p$-value 0,002 dan ada hubungan dukungan keluarga dalam mengontrol kadar gula darah nilai $\rho$-value 0,001 diperoleh nilai $p<0,05$. Kesimpulan: Terdapat hubungan yang bermakna pengetahuan dan dukungan keluarga dengan rutinitas dalam mengontrol gula darah pada penderita Diabetes Melitus tipe 2 di Wilayah Kerja Puskesmas Mangasa Kota Makassar
\end{abstract}

Kata Kunci : Diabetes Mellitus, Dukungan Keluarga, Gula darah, Pengetahuan

\title{
PENDAHULUAN
}

Kemajuan teknologi saat ini membuat manusia kurang melakukan aktivitas, teknologi membuat semua serba cepat dan praktis, kemudian membawa manusia kearah gaya hidup sidentary lifestyle atau aktivitas fisik yang kurang, sehingga terjadi pergeseran dari penyakit menular ke penyakit degeneratif salah satunya adalah Diabetes Mellitus yang pravelensinya dari tahun ke tahun mengalami peningkatan. Angka kesakitan dan kematian akibat penyakit tidak menular salah satunya adalah penyakit diabetes melitus yang menyerang secara perlahan-lahan. Saat ini Diabetes sudah menjadi masalah kesehatan bagi masyarakat diberbagai negara, termasuk Indonesia. Diabetes dapat berakibat fatal dan merambat kepenyakit lainnya jika tidak ditangani dengan benar (Nursyamsiyah, 2017).

Sebanyak $90 \%$ penderita Diabetes di seluruh dunia adalah penderita Diabetes tipe 2 yang sebagian besar dikarenakan kelebihan berat badan dan kurangnya aktivitas fisik. World Health Organization (WHO) memproyeksikan Diabetes akan menjadi salah satu penyebab utama kematian, karena jumlahnya yang mengalami peningkatan. Indonesia menduduki negara peringkat ke-4 terbesar dengan pertumbuhan penderita Diabetes sebesar $152 \%$ atau dari 8.426 .000 orang pada tahun 2000 menjadi 21.257 .000 orang pada tahun 2030 (WHO, 2015).

Menurut hasil Riset Kesehatan Dasar (Riskesdas) tahun 2018, prevalensi DM di Indonesia terjadi peningkatan yaitu dari tahun 2013 sebesar 6,9\% pada tahun 2018. Dari hasil Riskesdas 2018, prevelensi DM menurut konsensus Perkeni 2011 pada penduduk $\geq 15$ tahun 2013 dan tahun 2018 menunjukkan kasus DM (berdasarkan pemeriksaan darah) meningkat dari 6,9\% menjadi 8,5\% . Sedangkan menurut konsensus pada 2015 pada penduduk umur $\geq 15$ tahun pada 2018 menunjukkan kasus DM sebesar 10,9\%. 
Dinas Kesehatan Provinsi Sulawesi Selatan (Dinkes Sul-sel) pada tahun 2013 prevalensi Diabetes di Sulawesi Selatan yang didiagnosis dokter sebesar 1,6\% dan $0,5 \%$. DM yang didiagnosis dokter atau berdasarkan gejala sebesar 3,4\%. Prevalensi Diabetes yang didiagnosis dokter tertinggi terdapat di Kabupaten Pinrang (2,8\%), Kota Makassar (2,5\%), Kabupaten Toraja Utara (2,3\%), dan Kota palopo (2,1\%). Prevalensi Diabetes yang didiagnosis dokter atau berdasarkan gejala,tertinggi di Kabupaten Tanah Toraja (6,1\%), Kota Makassar (5,3\%), Kabupaten Luwu (5,2\%), dan Kabupaten Luwu Utara (4,0\%). Prevalensi Diabetes Mellitus,di Perkotaan cenderung lebih tinggi dari pada di Pedesaan. Berdasarkan data Survailans penyakit tidak menular bidang P2PL dinas kesehatan provinsi Sulawesi selatan tahun 2014 terdapat Diabetes Mellitus 27,470 kasus baru, 66.780 kasus lama dan 747 kematian (Diskes Sulsel, 2014).

Keluarga merupakan bagian terpenting bagi semua orang. Begitu pula bagi penderita Diabetes mellitus. Disadari atau tidak, saat seseorang mengalami Diabetes Mellitus maka mereka akan mengalami masa-masa sulit. Mereka harus mulai berbenah diri, mulai mengontrol pola makan dan aktifitas. Hal tersebut pasti sangat membutuhkan bantuan dari orang sekitar terutama keluarga, dengan menceritakan kondisi Diabetes mellitus pada orang terdekat, maka akan membantu dalam kontrol diet dan program pengobatan. BPOM RI (2006) menjelaskan bahwa faktor lingkungan dan keluarga merupakan faktor yang berpengaruh dalam menumbuhkan kepatuhan pasien. Dari pernyataan tersebut dapat dilihat bahwa orang terdekat dalam hal ini adalah keluarga mempunyai peranan untuk membantu penderita Diabetes mellitus dalam melakukan upaya pencegahan komplikasi Diabetes Mellitus. Dukungan keluarga melingkupi empat aspek yaitu dukungan informasi, emosional, penilaian, serta instrumental yang sangat berguna untuk mendukung pasien dalam melaksanakan pengendalian DM yang tepat (Wardani AK, Isfandiari MA, 2014).

Selain dukungan keluarga, pengetahuanpun juga sangat penting terhadap kesembuhan pasien. Pengetahuan pasien tentang DM merupakan sarana yang dapat membantu penderita menjalankan penanganan diabetes sehingga semakin banyak dan semakin baik pasien DM mengetahui tentang diabetes melitus, kemudian selanjutnya mengubah perilakunya, akan dapat mengendalikan kondisi penyakitnya sehingga ia dapat hidup lebih lama dengan kualitas hidup yang baik. Berbagai penelitian menunjukan bahwa tingkat pengetahuan penderita DM masih rendah (Waspadji, 2005).

Berdasarkan penelitian sebelumnya yang dilakukan oleh Isna Raditya Ningrum tahun 2018 dengan judul Hubungan Dukungan Keluarga dan Tingkat Pengetahuan dengan Kualitas Hidup Pasien DM Tipe 2 di Puskesmas Nogosari, Boyolali didapatkan hasil terdapat hubungan antara dukungan keluarga dan pengetahuan dengan kualitas hidup pada pasien Diabetes Mellitus di Puskesmas Nogosari Boyolali, yaitu semakin tinggi dukungan keluarga dan pengetahuan pasien maka kualitas hidupnya semakin meningkat.

Penelitian lain yang dilakukan oleh Lintang Hayu Pangestu tahun 2018 Dengan Judul Hubungan Antara Pengetahuan Dan Dukungan Keluarga Dengan Kepatuhan Menajalankan Diet Pada Penderita Diabetes Mellitus di Wilayah Puskesmas Baki Sukoharjo didapatkan hasil penelitian menunjukkan pengetahuan tidak ada hubungan dengan kepatuhan menjalankan diet Diabetes Mellitus, sedangkan untuk dukungan keluarga menunjukkan ada hubungan dengan kepatuhan responden dalam menjalankan diet Diabetes Mellitus. 
Tujuan dari penelitian ini untuk mengetahui Hubungan Pengetahuan Dan Dukungan Keluarga Dengan Rutinitas Dalam Mengontrol Gula Darah Pada Penderita Diabetes Mellitus Tipe 2 Di Wilayah Kerja Puskesmas Mangasa Kecamatan Rappocini Kota Makassar

\section{METODE}

Jenis penelitian ini adalah deskriptif analitik penelitian ini mencari hubungan antar variabel yang akan diteliti, menggunakan desain cross sectional. Desain penelitian cross sectional merupakan suatu penelitian yang mempelajari korelasi antara paparan atau faktor risiko (independen) dengan akibat atau efek (dependen), dengan pengumpulan data dilakukan bersamaan secara serentak dalam satu waktu antara faktor risiko dengan efeknya (point time approach), artinya semua variabel baik variabel independen maupun variabel dependen diobservasi pada waktu yang sama. (Masturod \& Anggita, 2018).

Populasi dalam penelitian adalah penderita Diabetes Melitus Tipe 2 yang terdata kunjungan di wilayah kerja Puskesmas Mangasa Kecamatan Rappocini Kota Makassar pada Bulan Januari 2019 yakni 102 orang. Sampel dalam penelitian ini yaitu 50 orang. Teknik sampling yang digunakan dalam penelitian ini adalah teknik Random Sampling.

\section{HASIL DAN PEMBAHASAN}

Hasil dan pembahasan disajikan dalam satu bagian yang terdiri dari beberapa paragraf. Bagian ini merupakan bagian yang paling dominan dari keseluruhan artikel, yaitu $60 \%$. Untuk memudahkan pemahaman dan pembacaan, hasil penelitian dideskripsikan terlebih dahulu, dilanjutkan bagian pembahasan. Subjudul hasil dan pembahasan disajikan terpisah.

Hasil

Tabel 1

Distribusi Frekuensi Responden Berdasarkan Kategori Pengetahuan

\begin{tabular}{ccc}
\hline Pengetahuan & $\begin{array}{c}\text { Frekuensi } \\
\text { (f) }\end{array}$ & Persentase\% \\
\hline Baik & 46 & 92,0 \\
Kurang & 4 & 8,0 \\
Baik & & \\
\hline Total & 50 & 100,0 \\
\hline
\end{tabular}

Dari Tabel 1 diatas menunjukkan bahwa dari 50 jumlah responden terdapat 46 $(92,0 \%)$ responden yang pengetahuan baik mengenai DM, sebanyak 4 orang $(8,0 \%)$ responden yang pengetahuan kurang baik mengenai DM.

Sumber : Data Primer 2019 
Tabel 2

Distribusi Frekuensi Responden Berdasarkan Kategori Dukungan Keluarga

\begin{tabular}{ccc}
\hline $\begin{array}{c}\text { Dukungan } \\
\text { Keluarga }\end{array}$ & $\begin{array}{c}\text { Frekuensi } \\
\text { (f) }\end{array}$ & Persentase\% \\
\hline Mendukung & 43 & 86,0 \\
Kurang & 7 & 14,0 \\
Mendukung & & \\
\hline Total & 50 & 100,0 \\
\hline
\end{tabular}

Dari Tabel 2 diatas menunjukkan bahwa dari 50 jumlah responden terdapat 43 orang $(86,0 \%)$ responden yang memiliki dukungan keluarga yang mendukung, dan sebanyak 7 orang $(14,0 \%)$ responden yang memiliki dukungan keluarga yang kurang mendukung.

Sumber : Data Primer 2019

Tabel 3

Distribusi Frekuensi Responden Berdasarkan Rutinitas Kontrol Gula Darah

\begin{tabular}{lll}
\hline $\begin{array}{l}\text { Kontrol Gula } \\
\text { Darah }\end{array}$ & $\mathrm{N}$ & $\%$ \\
\hline Rutin & 45 & 90,0 \\
Tidak Rutin & 5 & 10,0 \\
\hline Total & 50 & 100,0 \\
\hline
\end{tabular}

Dari Tabel 3 diatas menunjukkan bahwa dari 50 jumlah responden, terdapat 45 orang $(90 \%)$ penderita DM tipe 2 yang rutin mengontrol gula darahnya, dan terdapat 5 orang (10\%) penderita DM tipe 2 yang tidak rutin mengontrol gula darahnya.

Tabel 4

Distribusi Frekuensi Responden Berdasarkan Kategori Pengetahuan Dengan Rutinitas Mengontrol Gula Darah

\begin{tabular}{|c|c|c|c|c|c|c|c|}
\hline \multirow{3}{*}{ Pengetahuan } & \multicolumn{4}{|c|}{$\begin{array}{l}\text { Komtrol Kadar } \\
\text { Gula Darah }\end{array}$} & \multirow{2}{*}{\multicolumn{2}{|c|}{ Jumlah }} & \multirow{2}{*}{$\begin{array}{c}p \\
\text { Value }\end{array}$} \\
\hline & \multicolumn{2}{|c|}{ Rutin } & \multicolumn{2}{|c|}{$\begin{array}{l}\text { Tidak } \\
\text { rutin }\end{array}$} & & & \\
\hline & $\mathrm{n}$ & $\%$ & $\mathrm{n}$ & $\%$ & $\mathrm{n}$ & $\%$ & \\
\hline Baik & 44 & 97.8 & 2 & 40.0 & 46 & 9.2 & \\
\hline $\begin{array}{c}\text { Kurang } \\
\text { Baik }\end{array}$ & 1 & 2.2 & 3 & 60.0 & 4 & 8.0 & 0,002 \\
\hline Jumlah & 45 & 90.0 & 5 & 10.0 & 50 & 100 & \\
\hline
\end{tabular}


Hasil analisis bivariat dengan chi square berdasarkan tabel 4 didapatkan bahwa responden dengan pengetahuan baik tentang DM dan rutin kontrol gula darah sejumlah 44 orang $(97,8 \%)$, responden kurang baik dan rutin mengontrol gula darah sebanyak 1 orang (2.2\%). Sedangkan responden dengan pengetahuan baik tentang DM memiliki kontrol kadar gula darah yang tidak rutin sejumlah 3 orang $(60.0 \%)$ dan responden dengan pengetahuan baik dan tidak rutin kontrol gula darah sebanyak 2 orang (40,0\%). Hasil uji Statistik didapatkan $\mathrm{p}$ value $=0,002(\mathrm{p} \leq 0,05)$ yang artinya ada hubungan pengetahuan dengan rutinitas mengontrol gula darah pada penderita diabetes mellitus Di Wilayah Kerja Puskesmas Mangasa Kecamatan Rappocini Kota Makassar.

Tabel 5

Distribusi Frekuensi Responden Berdasarkan Kategori Dukungan Keluarga Dengan Rutinitas Mengontrol Gula Darah

\begin{tabular}{|c|c|c|c|c|c|c|c|}
\hline \multirow{3}{*}{$\begin{array}{l}\text { Dukungan } \\
\text { Keluarga }\end{array}$} & \multicolumn{4}{|c|}{$\begin{array}{l}\text { Komtrol Kadar } \\
\text { Gula Darah }\end{array}$} & \multirow{2}{*}{\multicolumn{2}{|c|}{ Jumlah }} & \multirow{3}{*}{$\begin{array}{c}p \\
\text { Value }\end{array}$} \\
\hline & \multicolumn{2}{|c|}{ Rutin } & \multicolumn{2}{|c|}{$\begin{array}{l}\text { Tidak } \\
\text { rutin }\end{array}$} & & & \\
\hline & $\mathrm{n}$ & $\%$ & $\mathrm{n}$ & $\%$ & $\mathrm{n}$ & $\%$ & \\
\hline Mendukung & 42 & 97.7 & 1 & 2.3 & 46 & 86.0 & \\
\hline $\begin{array}{c}\text { Kurang } \\
\text { Mendukung }\end{array}$ & 3 & 42.9 & 4 & 57.1 & 4 & 14.0 & 0,001 \\
\hline Jumlah & 45 & 90.0 & 5 & 10.0 & 50 & 100 & \\
\hline
\end{tabular}

Hasil analisis bivariat dengan chi square berdasarkan tabel 5 didapatkan bahwa responden dengan dukungan keluarga yang mendukung dan rutin mengontrol gula darah sebanyak 42 orang (97.7\%). Sedangkan responden dengan dukungan keluarga yang kurang mendukung dan rutin mengontrol gula darah sebanyak 3 orang (42.9.\%). Sedangkan responden yang memiliki dukungan keluarga yang mendukung namun tidak rutin dalam mengontrol gula darah sebanyak 1 orang $(2.3 \%)$ serta responden yang memiliki dukungan keluarga yang kurang mendukung dan tidak rutin mengontrol gula darah sebanyak 4 orang $(10.0 \%)$. Hasil uji Statistik didapatkan $p$ value $=0,001(p \leq 0,05)$ yang artinya ada hubungan dukungan keluarga dengan rutinitas mengontrol gula darah Di Wilayah Kerja Puskesmas Mangasa Kecamatan Rappocini Kota Makassar.

\section{PEMBAHASAN}

\section{Pengetahuan}

Berdasarkan hasil penelitian yang telah dilakukan terhadap 50 orang responden, di ketahui bahwa sebagian besar memiliki pengetahuan kategori baik yaitu responden terdapat $46(92,0 \%)$ responden yang pengetahuan baik mengenai DM, sebanyak 4 orang $(8,0 \%)$ responden yang memiliki pengetahuan kurang baik mengenai DM. Responden dengan pengetahuan kategori baik mayoritas berpendidikan SMA sebanyak 18 responden sehingga dengan pendidikan yang dimiliki cukup mudah untuk menerima informasi dan menentukan tindakan dalam mengontrol kadar gula darah. Soekanto, (2002) mengatakan pengetahuan merupakan hasil dari tahu, merupakan domain yang penting dalam membentuk tindakan seseorang (over behaviour). Hal ini sesuai dengan penelitian 
Ananda.AP dkk (2013) bahwa dengan pengetahuan yang baik, kadar glukosa darahnya lebih terkendali dibanding dengan yang memiliki pengetahuan kurang.

\section{Dukungan keluarga}

Berdasarkan penelitian yang telah dilakukan, dukungan keluarga responden sebagian besar dalam kategori mendukung yaitu 43 orang $(86,0 \%)$ responden yang memiliki dukungan keluarga yang mendukung, ini menunjukkan bahwa responden tersebut memiliki dukungan keluarga yang baiik karena keluarga memberi dukungan informasional, dukungan penilaian, dukungan instrumental serta dukungan emosional pada penderita diabetes melllitus sehingga penderita dapat menerima kondisinya, menambah rasa percaya diri, menurunkan stress dan mau berobat dengan teratur untuk kualitas hidupnya dengan rutin melakukan kontrol kadar gula darah untuk mencegah terjadinya komplikasi. (Hensarling, 2009) dalam (Priharianto, 2014) Faktor yang penting dalam kepatuhan manajemen penyakit kronik baik remaja maupun dewasa adalah dukungan keluarga. Dukungan keluarga merupakan indikator yang kuat yang dapat memberikan suatu dampak positif terhadap perawatan diri pada pasien dengan diabetes Mellitus.

Hasil penelitian ini didukung oleh penelitiann Ervy Tamara dkk, hasil penelitian ini menunjukkan adanya hubungan dukungan keluarga dan kualitas hidup pasien DM tipe 2. Dukungan keluarga mampu meningkatkan kualitas hidup bagi penderita DM tipe 2 dikarenakan dukungan keluarga diberikan dalam bentuk emosional, instrumental, penhargaan dan informasi yang mampu memberikan rasa nyaman dan dapat meningkatkan motivasi pasien dalam menjalani pengobatan dan perawatan diri yang akan mempengaruhi kualitas hidup diabetisi menjadi lebih baik.

\section{Kontrol gula darah}

Hasil penelitian menunjukkan sebagian besar penderita melakukan kontrol gula darah yakni dari 50 jumlah responden, terdapat 45 orang (90\%) penderita DM tipe 2 yang rutin mengontrol gula darahnya, berarti responden rajin dalam melakukan pemantauan kadar gula darah, hal ini sangat baik karena akan mencegah terjadinya peningkatan kadar gula darah agar terkontrol dan mencegah terjadinya komplikasi. Hasil pemeriksaan gula darah sangat bervariasi, tergantung metabolisme makanan menjadi gula oleh tubuh, serta bagaimana tubuh mengolah gula. (Tandra, 2017).

Hasil penelitian yang mendukung penelitian Nanang.M dkk (2016) yang mengatakan bahwa tidak hanya pengetahuan yang perlu dimiliki keluarga namun juga aplikasi dari pengetahuan yaitu sikap yang mereka miliki, misalnya mereka tahu bahwa penderita diabetes mellitus perlu mengendalikan pola makannya, untuk itu mereka juga mau mengontrol makanan oleh penderita diabetes, mengajak kontrol rutin ke sarana kesehatan, berolahraga sesuai jadwal dan minum obat rutin serta menghilangkan stress. Sehingga kemumgkinan kadar gula darah terkendali dan komplikasi terhindarkan.

\section{Hubungan pengetahuan dengan rutinitas mengontrol gula darah}

Hasil analisis bivariat dengan chi square berdasarkan penelitian yang di lakukan didapatkan bahwa responden dengan pengetahuan baik tentang DM memiliki rutinitas kontrol gula darah yang terkontrol sejumlah 44 orang $(97,8 \%)$, sedangkan responden dengan pengetahuan kurang baik tentang DM memiliki rutinitas kontrol gula darah yang 
tidak terkontrol sejumlah 3 orang $(60.0 \%)$. Hasil uji Statistik didapatkan $p$ value $=0,002$ $(p \leq 0,05)$ yang artinya ada hubungan pengetahuan dengan rutinitas mengontrol gula darah pada penderita diabetes mellitus Di Wilayah Kerja Puskesmas Mangasa Kecamatan Rappocini Kota Makassar.

Hasil penelitian menunjukkan semakin baik pengetahuan penderita diabetes mellitus membuat semakin mengontrol kadar gula darahnya, hal ini dapat dikarenakan pengetahuan yang dimiliki penderita diabetes mellitus akan berpengaruh terhadap motivasi dan perawatan pasien dengan diabetes mellitus sehingga lebih rutin mengontrol kadar gula darahnya agar terkendali untuk mencegah terjadinya komplikasi.

Hasil penelitian ini sejalan dengan teori (Smeltzer, et al. 2008) mengatakan bahwa Pendidikan pada pasien DM diperlukan karena penatalaksanaan DM memerlukan perilaku penanganan yang khusus seumur hidup. Pasien tidak hanya belajar keterampilan untuk merawat diri sendiri guna menghindari fluktuasi kadar glukosa darah yang mendadak, tetapi juga harus memiliki perilaku preventif dalam gaya hidup untuk menghindari komplikasi diabetik jangka panjang. Pasien harus mengerti mengenai nutrisi, manfaat dan efek samping terapi, latihan, perkembangan penyakit, strategi pencegahan, teknik pengontrolan gula darah dan penyesuain terhadap terapi.

Hal ini sesuai dengan penelitian sebelumnya oleh Anis Febriyani (2018), bahwa ada hubungan antara pengetahuan keluarga dengan tingkat kepatuhan kontrol gula darah pada penderita Diabetes Mellitus dengan nilai $\rho$ value $0,001<0,05$.

\section{Hubungan Dukungan keluarga dengan rutinitas mengontrol gula darah}

Hasil analisis bivariat dengan chi square berdasarkan didapatkan bahwa responden dengan dukungan keluarga yang mendukung dalam rutinitas mengontrol gula darah sebanyak 42 orang $(97.7 \%)$. Sedangkan responden dengan dukungan keluarga yang kurang mendukung dalam rutinitas mengontrol gula darah sebanyak 5 orang (10.0\%).Hasil uji Statistik didapatkan $\mathrm{p}$ value $=0,001(\mathrm{p} \leq 0,05)$ yang artinya ada hubungan dukungan keluarga dengan mengontrol kadar gula darah Di Wilayah Kerja Puskesmas Mangasa Kecamatan Rappocini Kota Makassar.

Hasil penelitian menunjukkan semakin baik dukungan keluarganya penderita diabetes mellitus membuat semakin patuh mengontrol kadar gula darahnya, hal ini dapat dikarenakan dukungan keluarga yang mendukung diabetisi akan membuat penderita diabetes mellitus dapat menerima kondisinya, menambah rasa percaya diri, menurunkan stress dan mau berobat dengan teratur untuk kualitas hidupnya dengan rutin melakukan kontrol kadar gula darah untuk mencegah terjadinya komplikasi.

Hasil penelitian ini sejalan dengan teori yang dikemukakan oleh (Setiadi, 2008) dalam (Priharianto, 2014).Manfaat dukungan sosial keluarga terhadap kesehatan secara spesifik terbukti dapat menurunnya mortalitas, lebih mudah sembuh dari sakit yang dialami, meningkatkan fungsi kognitif, fisik, dan kesehatan emosi atau psikologi. Selain itu pengaruh positif dari dukungan sosial keluarga ialah terdapat pada penyesuain terhadap kejadian dalam kehidupan yang penuh dengan stress (Setiadi, 2008) dalam (Priharianto, 2014).

Hasil penelitian ini sesuai dengan penelitian sebelumnya Penelitian yang pernah dilakukan H. Putri , F. Yeni, T. Handayani et al. (2013), Hasil penelitian menunjukkan terdapat hubungan yang bermakna antara hubungan peran keluarga dengan pengendalian kadar gula darah pada pasien Diabetes Mellitus $(\rho<0.05)$. Berdasarkan hasil penelitian 
didapatkan peran keluarga mempunyai peranan dalam pengendalian kadar gula darah. Oleh karena itu diharapkan keluarga meningkatkan keikutsertaan dalam merawat dan mendukung pasien diabetes mellitus dalam mengendalikan kadar supaya kadar gula darah dalam keadaan terkendali.

\section{SIMPULAN}

Terdapat hubungan yang signifikan antara Pengetahuan Dan Dukungan Keluarga Dengan Rutinitas Dalam Mengontrol Gula Darah Pada Penderita Diabetes Mellitus Tipe 2 Di Wilayah Kerja Puskesmas Mangasa Kecamatan Rappocini Kota Makassar

\section{Daftar Pustaka}

Benjamin, 2010. Derms Notes Dermatologi Clinical I Pocked Guide. Philadelphia: F.A. Davis Company. 98-100.

Chiptarini, I. F. D. (2014). Gambaran Pengetahuan Dan Perilaku Tentang Penatalaksanaan DM Pada Pasien DM Di Puskesmas Ciputa Timur.

Damayanti, S. 2015. Diabetes Mellitus Dan Penatalaksanaan Keperawatan.. Yogyakarta: Nuha Medika.

DINKES. (n.d.). Profil kesehatan provinsi sulawesi sealatan 2014.

Fatimah, R, N. 2015. Diabetes Melitus Tipe 2. J Majority vol 4 no 5 pg 101-93.

Febriyani, A. (2017). Hubungan Tingkat Dukungan Dan Pengetahuan Keluarga Dengan Tingkat Kepatuhan Kontrol Gula Darah Pada Penderita Diabetes Melitus Di Wilayah Kerja Puskesmas Jayengan Kota Surakarta.

Febriyani, A. (2017). Hubungan Tingkat Dukungan Dan Pengetahuan Keluarga Dengan Tingkat Kepatuhan Kontrol Gula Darah Pada Penderita Diabetes Melitus Di Wilayah Kerja Puskesmas Jayengan Kota Surakarta. Skripsi. Surakarta: Universita Muhammadyah Surakarta.

Harnilawati. (2013). Konsep Dan Proses Keperawatan Keluarga. Takalar: Pustaka As Salam.

Harahap, A. S. (2014). Gambaran glukosa darah setelah latihan fisik pada tikus wistar diabetes melitus yang diinduksi aloksan. Skripsi. Padang: Universitas Andalas.

IDF. (2017). IDF DIABETES ATLAS.

Jhonson \& Leny, R. (2010). Keperawatan Keluarga.Yogyakarta : Nuha Medika

Kemenkes. (2017). Buku_Rencana_Aksi_Nasional_2015_2019 (1).pdf.

Masturoh, I. \& Anggita, N. (2018). Metodologi Penelitian Kesehatan. Jakarta : Pusat Pendidikan Sumber Daya Manusia Kesehatan.

Mcculloch, D, 2009. Patient Information: Self-Blood Glucose Monitoring In Diabetes Melitus. Available from: http://www.uptodate.com/contents/patient- 


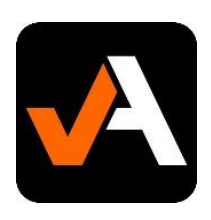

Volume : 07

Nomor : 01

Bulan : Januari

Tahun : 2021

http://ejurnal.pps.ung.ac.id/index.php/AKSARA/index

informationself-blood-glucosemonitoring-in diabetesmelitus [Accessed14Februari 2019].

Notoatmodjo. (2015). Metodologi Penelitian Kesehatan. Jakarta: Rineka Cipta.

Nursalam. (2016). Metodologi Penelitian Ilmu Keperawatan: Pendekatan Praktis. Ed. 4. Jakarta: Salemba Medika.

Nursyamsiyah. 2017. Berdamai Dengan Diabetes. Jakarta : Bumi Medika.

Padila. (2012). Keperawatan Keluarga Dilengkapi Aplikasi Kasus Askep Keluarga Terapi Herbal dan Terapi Modalitas. Yogyakarta: Nuha Medika.

Putra, A. L. (2015). Gambaran Kadar Gula Darah Sewaktu Pada Mahasiswa Angkatan 2015 Fakultas Kedokteran Universitas Samratulangi Manado. E-Biomedik (EBm), Vol.3 No.3, hh.835.

Priharianto, A. (2014). Hubungan Antara Dukungan Keluarga Dengan Keteraturan Kontrol Kadar Gula Darah Pada Penderita Diabetes Melitus Di Wilayah Puskesmas Bendosari Sukoharjo.

Rumahorbo, H. (2014). Mencegah Diabetes Melitus Dengan Perubahan Gaya Hidup. Bogor : In Media.

Riskesdas. (2018). Dipetik 13 Februari, 2019 dari Hasil Riset Kesehatan Dasar : http://www.depkes.go.id/resources/download/infoterkini/materi_rakorpop_20 18/Hasil\%20Riskesdas\%202018.pdf.

Siyoto, S. \& Sodik, M. A. (2015). Dasar Metodologi Penelitian. Yogyakarta: Literasi Media Publishing.

Soegondo, S., Soewondo, P., \& Subekti, I. (2015). Penatalaksanaan Diabetes Terpadu Edisi Kedua. Jakarta: Balai Penerbit FKUI.

Tandra, H. (2017). Segala Sesuatu Yang Harus Anda Ketahui Tentang Diabetes Panduan Lengkap Mengenal Dan Mengatasi Diabetes Dengan Cepat Dan Mudah Edisi Kedua Dan Paling Komplit. Jakarta: PT Gramedia.

Pratiwi, T, P.2017. Faktor- faktor yang berpengaruh terhadap kejadian Diabetes Mellitus Pada Wanita Usia Subur Di RSUD DR.Djolham Binjai. Tesis .Medan : Universitas Sumatra Utara.

Wordl Health Organization, (2016). Epidemiological Situation. Retrieved from https://www.who.int/leishmaniasis/burden/en/. 


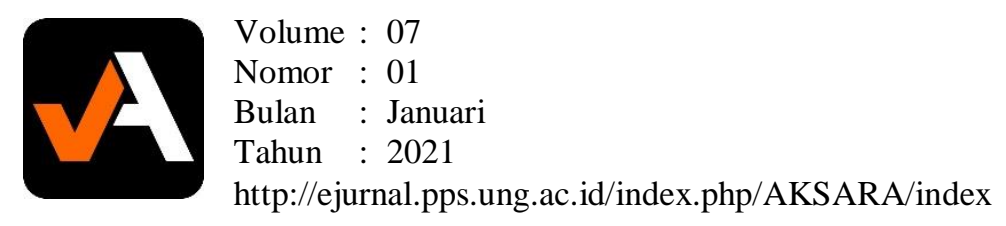

Wardani, A.K., \& Isfandiari, M.A. (2014). Hubungan Dukungan Keluarga dan Pengendalian Kadar Gula Darah dengan Gejala Komplikasi Mikrovaskuler. Jurnal Berkala Epidemiologi. Surabaya: Departemen Epidemiologi Fakultas Kesehatan Masyarakat Universitas Airlangga. Vol. 2, No. 1. Diakses 21 Agustus 2015 dari http://journal.unair.ac.id/download-fullpapersjbef4166aa5ccfull.pdf.

Waspadji, S. 2005. Diabetes Mellitus: Mekanisme dasar dan Pengelolaannya yang Rasional. Dalam Soegondo s. Penatalaksanaan Diabetes Mellitus Terpadu Penerbit. FKUI. Jakarta.

Wordl Health Organization, (2016). Epidemiological Situation. Retrieved from https://www.who.int/leishmaniasis/burden/en/.

Wijaya, AS dan Putri, YM. 2013. Keperawatan Medikal Bedah (Keperawatan Dewasa). Yogyakarta : Nuha Medika.

Yahya, N. 2018. Hidup Sehat Dengan Diabetes. Solo : Metagraf, Imprint of Tiga Serangkai.

Yusra, A. 2011. Hubungan Antara Dukungan Keluarga Dengan Kualitas Hidup Pasien Diabetes Melitus Tipe 2 Di Poliklinik Penyakit Dalam Rumah Sakit Umum Pusat Fatmawati. Tesis. Jakarta: Fakultas Ilmu Keperawatan Universitas Indonesia.

Yusuf. M. PH, S. F. (2015). Metodologi Penelitian Kesehatan. Padang, Sumatera: Darmais Press. 
Volume : 07

Nomor : 01

Bulan : Januari

Tahun : 2021

http://ejurnal.pps.ung.ac.id/index.php/AKSARA/index

78 AKSARA: Jurnal IImu Pendidikan Nonformal 